\title{
RETÓRICA DA IMAGEM URBANA EM MÍDIAS DE INFORMAÇÃO COMO LUGARES: A VISIBILIDADE TURÍSTICA EM BALNEÁRIO CAMBORIÚ, SC, BRASIL
}

\author{
RHETORIC OF THE URBAN IMAGE IN MEDIA OF INFORMATION AS \\ PLACES: THE TOURISTIC VISIBILITY IN \\ BALNEÁRIO CAMBORIÚ, SC, BRASIL
}

Josildete Pereira de Oliveira - joliveira@univali.br Luciano Torres Tricárico - lttorres@usp.br Professores da Universidade do Vale do Itajaí - UNIVALI

Flávia Monteiro Pereira - fla monteiro@terra.com.br Estudante do Curso de Arquitetura e Urbanismo da UNIVALI Bolsista de Iniciação Científica do programa Artigo 170 do Governo do Estado de Santa Catarina, de 2006 a 2007.

\section{RESUMO}

Fatos que empobrecem a urbanidade podem partir da própria vontade de tornar a cidade legível nos seus significados físicos espaciais e pragmáticos para o turismo. São signos visuais imagéticos que, projetados a princípio, procuram a melhoria das cidades, mas que, com outros mecanismos, adquirem um potencial que enfraquece a condição urbana. Alguns destes mecanismos são decifrados na história da modernidade urbana com as novas mídias. Este artigo é resultado de reflexões decorrentes da atividade de pesquisa e da prática de ensino sobre a temática legibilidade da paisagem urbana. Mais especificamente, de um estudo de caso sobre a cidade de Balneário Camboriú - SC, pesquisa financiada pela UNIVALI / Artigo 170 Governo de Santa Catarina. O objetivo principal analisar a imagem urbana da orla de Balneário Camboriú, representada em mídias de informação (folders, postais, vídeos, mapas mentais). O método partiu do objeto representado - a cidade - como geradora de novas interpretações, embora considerando a relação entre o objeto representado e a teoria. Deste modo é que a leitura bibliográfica serviu para estimular a interpretação, entendendo-a como repertório informacional e não como mecanismo justificativo. Finalmente, a síntese procurou evidenciar os resultados da análise do objeto relacionando-o com o aporte teóricoconceitual.

Palavras-chave: Legibilidade urbana; Turismo e imagem urbana; Paisagem urbana e turismo; City-marketing.

\section{INTRODUÇÃO}

As cidades com vocações turísticas podem apresentar em suas formulações espaciais dados que tanto devem atender ao turista como os seus cidadãos. Porém, nesta lógica da economia turística, estas cidades também procuram a divulgação de seu produto - os lugares - através de mídias de divulgação que devem percorrer agências de viagens, cartazes, folders, programas televisivos, o cinema, o vídeo, a internet, etc. Com este intuito, a conformação dos espaços na cidade pode trabalhar sob condicionantes 
projetuais que se ligam muito mais ao ideal da imagem da propaganda turística do que, necessariamente, de espaços convenientes ao uso dos cidadãos ou até mesmo dos turistas.

Mas, ainda que se utilize desta prática de condicionar o projeto arquitetônico e urbano na lógica turística imagética, muitos deles poderão apresentar traços que, por outro lado, também inferem sobre uma relação de identidade entre o cidadão e o lugar criado; construindo, assim, uma noção de "pertencimento" do habitante para com lugares da cidade, ainda que pensados sob a lógica da imagem turística. Isto posto, o objetivo do trabalho foi identificar uma estrutura comum em diversos exemplos que ajudam a constituir uma idéia que atenda ao propósito turístico e que criam relações de cidadania. No estudo de caso sobre Balneário Camboriú procurou observar e inferir sobre a presença do city-marketing, através da dominante de interpretação da imagem urbana, ou seja, através da análise das imagens urbanas: mapas mentais dos entrevistados, residentes e turistas; material publicitário fornecido por agências de turismo e postais da cidade.

O uso da imagem de uma cidade pode se dar como "estratégia urbana" em eventuais "candidaturas" das cidades na competição por representatividade turística: exposições, programas de regeneração urbana de áreas centrais prevendo equipamentos culturais em complementaridade com outras cidades, competição por pólos de desenvolvimentos tecnológico, científico e de comunicações, acessibilidade, relações trabalhistas, tradição laboral, marketing político, calendários eleitorais, etc. Esta estratégia urbana, em algumas situações, pouco tem a ver com os interesses de gerar efetivos hábitos de ação social, mas sim de aproveitar a imagem de cidade para ser estampado mundo afora, através de agências de viagens, com a pretensão de obter visibilidade do espaço turístico e de negócios e, conseqüentemente, atrair investimentos e divisas (notadamente através do fluxo turístico) ${ }^{\mathrm{i}}$.

Pode-se aferir, a princípio, que a cidade de Balneário Camboriú, SC, Brasil, enquadra-se na perspectiva de divulgação turística que parte, essencialmente da condição de sua geografia através da balneabilidade das praias. Mas, por complementaridade ao programa de veraneio e do turismo de "sol e mar", a cidade vem trabalhando ultimamente na arquitetura de marcos visuais - equipamentos e espaços de uso coletivo - que se veiculam nas mídias especializadas para a divulgação da economia turística, atendo, com isto, por exemplo, um turismo complementar de entretenimento noturno.

Com isto, mais que o papel oferecido pelos atrativos naturais, há um papel desenvolvido pela arquitetura e urbanização que denotam a apropriação de um city-marketing que proporcionará dados e condicionantes de projeto que vão além da leitura do lugar, mas operam na lógica da construção da "imagem atraente" do espaço, muito além da própria qualidade deste espaço para ser utilizado e vivenciado pelo cidadão local e turista.

Mesmo que os espaços urbanos não sejam tatilizados como uso efetivo, eles, por vezes, procuram recorrer a uma visualidade atraente veiculada em mídias que não são necessariamente interessadas na qualidade do espaço urbano; ainda assim, pode ocorrer o sentido de pertencimento dos cidadãos com estes espaços essencialmente "imagéticos". Conseqüentemente, as mídias que veiculam a propaganda turística podem, eventualmente, influenciar na construção de identificação de lugares para com os habitantes da cidade.

Entende-se a cidade como dado não verbal, o que caracteriza a busca da realidade do espaço socialmente construído como gerador de informação; assim, parte-se da leitura do espaço na tentativa de novas hipóteses na explanação deste texto. Por se tratar de sistema espacial, é notória sua plurisignificação inerente, originando uma gama de interpretações com várias possibilidades relacionais.

Enc. Bibli: R. Eletr. Bibliotecon. Ci. Inf., Florianópolis, n. esp., 2º sem. 2008 
Deve-se considerar que o método de pesquisa partiu do objeto representado, a cidade, como geradora de novas interpretações, embora considerando a relação entre o objeto representado e a teoria. Portanto, não se iniciou com a formulação de uma teoria que é aplicada ao objeto no intuito de deduzir alguma relação teórica, mas, parte-se do objeto representado, a cidade, como geradora de novas interpretações. Em determinados momentos da pesquisa ocorreu uma simultaneidade entre objeto representado e a teoria; deste modo é que a leitura bibliográfica serviu para estimular a interpretação, entendendo-a como repertório informacional e não como mecanismo justificativo. A dedução, então, associa-se à experiência empírica do objeto para possibilitar a verificação de sua formulação hipotética. Nesta relação entre o universo empírico e a construção de teorias, houve a necessidade da leitura do ambiente urbano e da paisagem edificada, representada graficamente em material iconográfico referente ao objeto de pesquisa - Balneário Camboriú. A leitura se deu inicialmente com a contextualização do material iconográfico e dos espaços urbanos elencados a partir do objeto da pesquisa que, por razões de um repertório adquirido, indicam a possível relação deles com o objetivo proposto. Esta fase compreendeu visitas periódicas aos lugares de estudo, uma varredura de fontes iconográficas e materiais que foram julgados como documento, em razão da pertinência do tempo e lugar destes estudos de caso. A etapa subseqüente procurou analisar o recorte do objeto urbano em questão.

Disto decorre a análise da cidade que se faz por representações de valores e usos num cotidiano físico existente que parece indiferente ao usuário por ser habitual. A operação da leitura procurou estabelecer os fatos que levam a um determinado uso urbano e, ao mesmo tempo, ordenar os significados representados dos lugares analisados. Este método esteve amparado por mapas mentais como recurso para informação não verbal, bem como a busca de fontes primárias iconográficas em bibliotecas e agências de viagem.

Principalmente através das agências de viagens as mídias especializadas operam na divulgação da propaganda turística, essencialmente o folder e os postais, tendo em vista suas características de veículo, formas de conformações espaciais que, em muitos casos, não são projetadas para serem apreendidas como uso efetivo. Por exemplo, amparar a fruição da paisagem urbana pelo pedestre ou incentivar o uso das áreas de estar como as praças, etc. Portanto, trata-se de uma organização espacial que surge como "cenário" a ser estampado no folder, no cartaz, no cinema, no vídeo, na televisão, na internet, ou seja, no "espaço imagético".

Desta maneira, a própria forma de assimilar as proposições espaciais advindas de arquitetos e urbanistas pode passar por uma revisão, na qual os condicionantes projetuais se sustentam muito mais na lógica imagética para a promoção de lugares. Trata-se, com isto, de elencar situações onde esta prática pode se apresentar como dado de interesse para os projetistas da cidade, no caso do projeto que só se faz para atender à propaganda turística; ou quando o espaço resultante também consegue agregar situações nas quais os cidadãos se identificam com o lugar, na medida em que ocorra também a construção da cidadania através da memória material que o espaço pode oferecer.

Como método interpretativo da pesquisa, a referência foram os estudos de Charles Sanders Peirce (1839-1914), filósofo norte-americano considerado o fundador da Semiótica, onde a lógica da representação se dá por signos que substituem o objeto, não propriamente em todos os seus aspectos, mas naqueles que se quer representar. $\mathrm{Na}$ seleção do que se pretende representar, é possível identificar uma intelecção, por parte do sujeito emissor, em propor ideologias. "Querer-se" representar indica ideologias do emissor e, depois de interpretadas como uso pelo receptor, também indica os valores deste; considerando-se, na análise, que a informação gerada pelo receptor não implica na total comunicação com o emissor; com isto, mais uma vez, a possibilidade de

Enc. Bibli: R. Eletr. Bibliotecon. Ci. Inf., Florianópolis, n. esp., 2º sem. 2008 
interpretar a razão pela qual não se deu o objetivo primeiro da emissão. Estes processos de representação, tanto como emissor ou receptor, revelam o repertório cultural dos sujeitos e produzem significados que, associados, podem desmembrar, alterar, reconsiderar as hipóteses formuladas no início e permitir possíveis generalizações ou interpretações que estão na raiz da linguagem espacial plurisignificativa.

\section{REFERENCIAIS TEÓRICOS DA PESQUISA}

\subsection{De volta ao lugar}

A sobreposição e saturação de imagens urbanas simbólicas na cidade nem sempre ocasionam a decodificação delas. Há um acúmulo de informação que necessariamente não se comunica no ambiente urbano, pois, de alguma forma, não houve uma leitura repertorial do lugar. Assim, por exemplo, a mudança de função da Estação Júlio Prestes em São Paulo, como sala para concertos musicais pode não ser lida como tal pela população do entorno imediato ou dos transeuntes e passageiros usuários dos trens. A Sala Júlio Prestes se decodifica, neste sentido, por mecanismos virtuais de divulgação, posto que as suas funções atingem níveis repertoriais de usuários que não "estão ali" efetivamente.

As imagens urbanas podem apresentar como dado de veiculação muito mais a "produção" turística do que necessariamente a cultura do cotidiano da população. O que pode acarretar um distanciamento entre a imagem gerada de cidade e os seus cidadãos.

Ou ainda a interpretação da cidade turística pode partir de grupos sociais quando do interesse para se levar em conta que a representação destes se faz em processos midiáticos que caracterizam novas noções para a idéia de território. É possível, então, identificar lugares, regiões, territórios espaciais a partir de dados abstratos de imagens virtuais, da música, da dança, do cinema, do vídeo, etc - eis a identidade cultural com suas delimitações espaciais. Neste sentido, para o objeto deste estudo, o Bairro da Barra em Balneário Camboriú, por se tratar de um território dos pescadores, pode ser alvo de estetização deste grupo caiçara com seus hábitos e arquiteturas características. De outra forma, estas práticas de "estetização" social e espacial podem promover o "enrijecimento" de um grupo social.

Esta problematização é uma manifestação que muitos lugares ou as cidades ou ainda regiões se encontram. Notável que é nas cidades que os diferentes grupos têm a oportunidade de se auto-afirmarem (SENNET, segundo BAUMAN, 2001,p. 11), pois sem este suporte de "comparação" a identidade talvez não precisasse ser hiperbolizada. Neste processo, o espaço pode operar como signo de diferenciação ao pertencer a um determinado grupo. Mas há ainda a possibilidade de pertencimento a diversos grupos pelo fato do sujeito utilizar uma máscara como possibilidade de sociabilidade (BAUMAN, 2001, p. 112), podendo assim circular pelos diversos lugares da cidade. É também neste sentido que o nomadismo terá explicação para a modernidade contemporânea. A questão está em porque só é possível entrar nos distintos territórios através da identidade com uma máscara. Parece que tal situação de simulacro do sujeito não era o que os ideólogos do espaço modernista assim pretendiam; tratou-se de uma passagem ou substituição do engajamento fixo e constante no lugar pelo pertencimento frívolo em momentos; mas que nos dois casos ainda se encontra uma estrutura comum do encontro social, participação e envolvimento público. Assim como a sociedade pode estar com máscara, o espaço, por vezes, também o está ou o é; eis o que explica o que se convencionou chamar pelo caráter "cenográfico" de uma arquitetura e espaços públicos "pós-modernos".

\subsection{Da teoria do lugar à realidade do lugar}

Enc. Bibli: R. Eletr. Bibliotecon. Ci. Inf., Florianópolis, n. esp., 2º sem. 2008 
As cidades com valores culturais e turísticos também podem ocasionar espaços homogêneos. Daí o surgimento de modalidades espaciais reconhecidas em escala mundial pelo valor simbólico: shoppings centers, centros de convenções, parques temáticos, centros culturais, museus que, em muitos casos estão "vazios" de sentido e são utilizados para receber grandes exposições internacionais, onde o evento é mais importante que as obras.

As cidades podem representar um Estado, uma nação, uma região, na era da informação e do mundo globalizado, ou até podem ultrapassar o estabelecimento diplomático do governo onde estão instaladas (DUARTE, 2002, p.191). As cidades consideradas globais são responsáveis pela prestação de serviços e, com eles, a importância da indústria cultural e turística; as empresas possuem serviços dedicados a divulgar e expandir os mercados culturais, o mercado de arte, a valorização do design, o uso do tempo livre para o lazer e turismo. Produz-se uma representação de cidade no mundo dos negócios e dos serviços que ampara a produção cultural e turística de uma demanda que atenda a exigência do público: melhor qualidade de vida, prestação de serviços de vanguarda, pessoal qualificado e disposto a aceitar as condições de vida oferecida nas cidades. A competição ou complementaridade entre elas no circuito dos negócios e serviços pode se confundir com os serviços de cultura e do turismo. Tal competição ou complementaridade não é necessariamente econômica, mas, também, por qualificação urbana espacial, de ofertas de empregos, universidades, etc, que poderão dar qualidade de vida a uma carreira promissora. Inclui-se, neste programa, a vida cultural, a qualidade da arquitetura, centros históricos preservados, segurança, transportes coletivos e alternativos, espaços para o ócio e lazer.

Estas formas espaciais, com forte apelo conotativo, foram inicialmente destinadas a sociedades que, de certo modo, passaram por todas as fases de produção capitalista e podem ser consideradas como populações pós-funcionais. A "mecanização muscular", valendo-se da metáfora de ordenação do espaço da Revolução Industrial Mecânica, cede lugar aos meios "sinápticos eletroeletrônicos", permitindo-se mais uma vez o uso da metáfora da Revolução Industrial Eletroeletrônica. O espaço físico real, em sua elaboração, parece carecer de mais significados do que apenas a mecanicidade funcional, daí a construção do espaço com valores conotativos.

Tratando-se de regiões consideradas periféricas no mundo do capital, mas com cidades que se projetam como cidades globalizadas, a assimilação de métodos de simbolização do espaço para representação mundial pode apresentar um descompasso com as reais necessidades de seus cidadãos. As questões verdadeiramente locais perdem o debate em confronto com o êxito e monumentalização de pontos estrategicamente escolhidos por sua visualidade perante outras cidades. Compete-se para atingir o título de "cidade turística" que é, em grande parte, uma invenção deste estágio do capital, ainda que se fale em valores locais para atendê-lo. A imagem da cidade é criada como representatividade daquilo que efetivamente ela não é, mas do que a cidade gostaria de ser - trata-se, nas expressões correntes de um city-marketing, com o intuito de atrair investimentos.

Como lembra Souza (2002), o problema está mesmo no marketing como "propaganda enganosa" onde as qualidades do "produto" cidade são evidenciadas e os defeitos são escondidos; mas a cidade não é um produto onde se limitam descrições de ordem mercadológicas adjetivadas; sua leitura é plurisignificativa e feita como sistema aberto onde coexistem várias. Assinala-se que o city-marketing tem incorrido por caminhos que não procuram esconder todos os problemas da cidade, pois, sob o "olhar" empresarial, isto pode causar melhor impressão e confiança do que uma imagem de cidade perfeita, parecendo falsa e artificial. De outra forma, o city-marketing não procura apenas os investidores, mas a promoção do administrador público, e servirá 
para demonstrar os resultados de seu trabalho, podendo contribuir para a sua legitimidade ou não; e, com isto, o aumento da auto-estima da população local. (SOUZA, 2002, p. 41).

\section{UM LUGAR: BALNEÁRIO CAMBORIÚ}

Na competição por visibilidade turística, a cidade de Balneário Camboriú, SC, Brasil pode ser interpretada como diferenciação de um lugar na lógica das cidades de veraneio do litoral catarinense, bem como de toda a costa brasileira. Esta "acentuação" do lugar se dá como imagem urbana construída a partir da verticalidade da paisagem edificada como signo de identidade do lugar.

Segundo Cullen (1991, p. 15), "uma rua que se prolonga à nossa frente sempre em linha reta tem um impacto relativamente pequeno, porque o panorama inicial é rapidamente assimilado, tornando-se monótono". Da mesma forma que a junção de edificações de mesmo porte na orla marítima, como acontece em Balneário Camboriú, uma ao lado da outra, também causa essa sensação de homogeneidade. A aproximação entre os prédios pode causar um sentimento de "pressão", estreitamento, ainda que estabeleça uma articulação da cidade, com espaços definidos e delimitados.

Num primeiro momento, pode-se dizer que um elemento vertical serve como marco visual, um ponto focal em relação ao entorno. Cria certa referência e legibilidade ao local. Porém, uma vez que aglutinado a infinitos deles, numa escala espacial restrita, faz perder esse significado. Não existe mais um ponto focal, uma referência, e sim uma "parede", barreira visual que impede a relação do usuário com o resto da cidade, na escala da rua. Essa característica também acontece com elementos horizontais, no caso de Balneário Camboriú, que cria uma "barreira", ou até um limite para a cidade; e o que está além dela deixa de ser considerada parte da cidade, tanto para os turistas como para os próprios moradores.

Ao analisar os postais e imagens de Balneário Camboriú, é possível perceber que, dependendo do ângulo da foto tirada, surge um ponto focal diferente, dificultando a legibilidade do usuário. Ou seja, em alguns ângulos de visão é possível identificar referências pontuais de edifícios que se fixam pela cor, proposição, monumentalidade, porém, por outras visuais, estes atributos podem se perder. Numa lógica visual com maior amplidão da imagem urbana, é possível identificar uma grande massa edificada, signo da localização e identidade do mar.

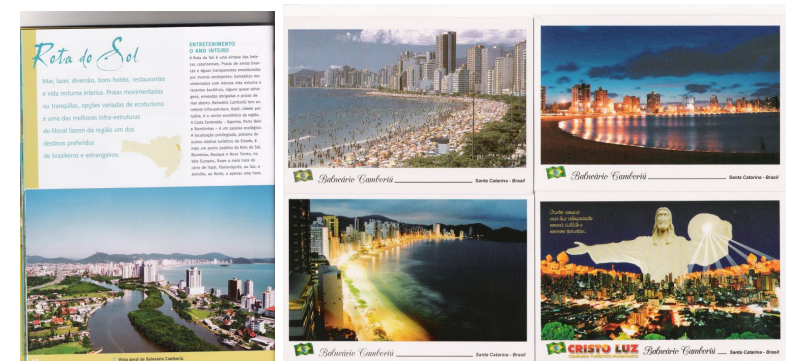

À esquerda: propaganda turística em folder de divulgação. Fonte: Agência de Turismo Acatur (UNIVALI); à direita: quatro cartões postais de Balneário Camboriú. Ênfase na verticalidade da imagem urbana como possível signo de progresso. Imagens de sobrevôo onde "poucos" turistas ou moradores conseguem perceber a cidade por estas visuais.

Para Lynch (1987) a imagem da cidade pode utilizar alguns elementos que as caracterize, trazendo àquele local legibilidade aos seus usuários. Um lugar legível é aquele em que seus marcos, vias e bairros são facilmente reconhecidos, permitindo-se

Enc. Bibli: R. Eletr. Bibliotecon. Ci. Inf., Florianópolis, n. esp., 2º sem. 2008 
uma locomoção mais fácil e rápida pela cidade. Além disso, pode servir como um vasto sistema de referências ou um organizador de atividades.

As vias são os canais de circulação deste local e seus habitantes observam-na à medida que se locomovem por ela, identificando ainda os outros elementos ambientais que ali se organizam e se relacionam. No caso de Balneário Camboriú, duas das principais vias de articulação da cidade são a Avenida Atlântica e a Avenida Brasil, onde a maioria das atividades sócio-culturais acontece, onde há o maior fluxos de pessoas e automóveis, dando a esta cidade um significado dinâmico.

Assim como Cullen (1991), Lynch também trabalha com o significado de limites, onde elementos lineares que representam a quebra da continuidade podem ter importantes características organizacionais para a cidade. O limite também adquire força se for lateralmente "visível" a alguma distância, se assinalar um gradiente legível das características de uma área e se ligar claramente duas regiões limítrofes. Para a cidade em questão, seus principais limites reconhecidos pelos seus moradores e usuários são as praias, morros, rio Camboriú e a BR-101.

Existem ainda aqueles locais considerados por Lynch (idem) como lugares estratégicos da cidade, ou seja, os pontos nodais. Podem ser junções, locais de interrupção do transporte, cruzamento ou convergência de vias. Esses pontos algumas vezes acabam tornando-se também marcos visuais, ou seja, referência para quem circula pela cidade. Esse marco vão desde um objeto físico ou elemento construído, até elementos naturais e podem estar dentro ou distante da cidade. Balneário Camboriú possui alguns marcos facilmente identificáveis, como a própria orla marítima, os morros, o "Cristo Luz", o teleférico, que trazem ao usuário o sentimento de referência para com a cidade.

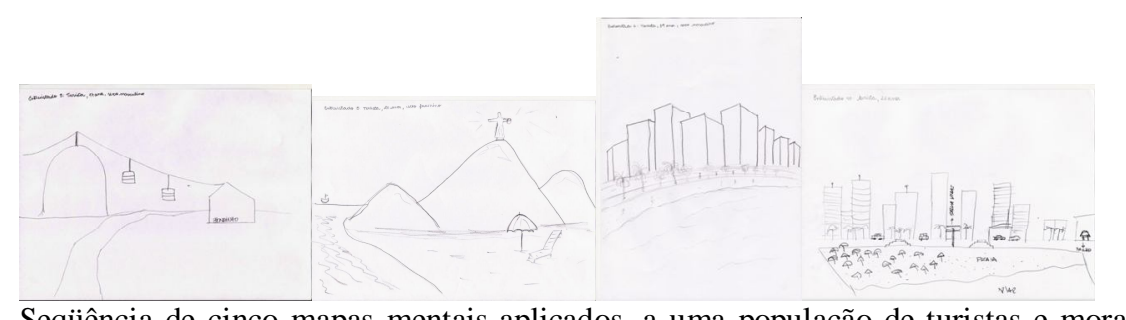

Seqüência de cinco mapas mentais aplicados, a uma população de turistas e moradores com diferentes faixas etárias, fazendo com que estes desenhassem o que melhor representasse ou lembrasse a cidade de Balneário Camboriú. O resultado apresentou a verticalidade como estrutura comum na análise dos desenhos. Assim surgiu a orla com os altos edifícios, o teleférico sobre o morro e o "Cristo Luz".

Para Ferrara (1996) não é possível à apreensão do espaço senão através dos usos e hábitos decorrentes do modo de produção que caracteriza o espaço. Além disso, espaço e informação estão intimamente ligados, ou seja, o espaço é o local que "agasalha" a informação e interfere na sua produção, mas sua homogeneidade não permite que ela se revele. A cidade de Balneário Camboriú é movida pelo turismo, pelo caráter universitário e ainda abriga uma grande quantidade de usuários com perfil de aposentados. Essas diferentes características fazem de seu espaço um local dinâmico e verticalizado, onde existe uma grande quantidade de pessoas para o "pouco" espaço disponível.

Ferrara (1986; 1996) também defende alguns elementos que são organizadores do lugar. Um deles é o significado de ícones, ou seja, imagens, diagramas e metáforas, que representam idéias, formalizam conhecimentos, possuem caráter representativo ou possuem similaridade de qualidade com o objeto. A visibilidade é a qualidade visual do lugar, e traduz a complexidade da orientação nas cidades. Essa característica representa a rapidez do reconhecimento desse espaço como lugar, e pode ser manipulada pelos 
agentes privados, públicos ou técnicos a fim de selecionar os pontos aprazíveis a serem mostrados, divulgados; e esconder os desagradáveis - aí que os postais e folders desenvolvem seu papel.

Assim como Lynch temos Ferrara (idem) que também trabalha a questão da legibilidade, em que a verticalização (e neste caso de estudo de Balneário Camboriú) aparece como metáfora do poder e da opulência. Existem dois tipos de imagens urbanas que nos levam à legibilidade do lugar. A primeira seriam as imagens de topo, ou seja, os volumes e visuais panorâmicos da cidade e a segunda seriam as imagens de base, onde se encontram as áreas verdes, símbolos empresariais, esculturas, recuos e até a diferenciação entre público e privado. Em Balneário Camboriú, a mídia tem manifestado sua freqüência nas imagens de topo.

\section{CONSIDERAÇÕES FINAIS}

A sobreposição e saturação de imagens urbanas simbólicas na cidade nem sempre ocasionam a decodificação delas. Há um acúmulo de informação que necessariamente não se comunica no ambiente urbano, pois, de alguma forma, não houve uma leitura repertorial do lugar. Assim, por exemplo, pode se dar com a preocupação arquitetônica "depositada" sobre um único edifício na orla de Balneário Camboriú, junto à Avenida Atlântica. Ele ali locado, no conjunto de imagem urbana, pode se "perder", pois se conforma conjuntamente com uma "grande parede" de edifícios enquanto síntese de percepção.

Mesmo que o espaço público não seja tatilizado, por vezes ele procura recorrer a uma visualidade atraente para se representar em mídias que não são necessariamente interessadas na qualidade do espaço urbano e, com isto, também pode ocasionar sentido de pertencimento aos cidadãos. Assim, a mediatização da imagem urbana de Balneário Camboriú, a partir de visais de "sobrevôo", se por um lado pode comprometer a relação de pertencimento na medida em que poucos conseguem visualisar a partir daqueles ângulos, por outro lado desperta o sentimento de orgulho de alguns residentes e / ou turistas na medida em que aquela visibilidade de "sobrevôo", que só as mídias podem revelar, garantem uma monumentalização. Nesta relação ambígua, a imagem de monumentalização parece ser o principal signo de orgulho de seus cidadãos e visitantes, conforme a pesquisa identificou na amostra da população enquetada. Com isso, a verticalidade excessivamente ressaltada na paisagem edificada, resultante de uma "estratégia urbana" apoiada na lógica da especulação imobiliária, tem operado também como a identidade do lugar.

\section{REFERÊNCIAS}

BAUMAN, Zygmunt. Modernidade líquida. Rio de Janeiro: Jorge Zahar, 2001. CULLEN, Gordon. Paisagem urbana. São Paulo: Ática, 1991.

DUARTE, Fábio. Crise das matrizes espaciais. São Paulo: Perspectiva/FAPESP, 2002.

FERRARA, Lucrécia D’Alessio. A estratégia dos signos: linguagem, espaço, ambiente urbano. São Paulo: Perspectiva, 1986.

FERRARA, Lucrécia D'Alessio. O turismo dos deslocamentos virtuais. In: TURISMO: espaço, paisagem e cultura”. São Paulo: Hucitec, 1996.

LYNCH, Kevin. A imagem urbana. Rio de Janeiro: Jorge Zahar, 1987.

SANTOS, Milton. A natureza do espaço: técnica e tempo, razão e emoção. São Paulo: Hucitec, 1996.

SOUZA, Marcelo Lopes de. Mudar a Cidade: uma Introdução Crítica ao Planejamento e à Gestão Urbanos. Rio de Janeiro: Bertrand Brasil, 2002. 


\begin{abstract}
Shapes that empoverish the urbanity can derive from their own intentions to make the city interpreted on its pragmatic of daily and physical meanings to the tourism. These are signs imagetic's visuals that projected at first look for the cities' improvement, but that, with other mechanisms, gets a potential which weakens the urban condition. Some of these mechanisms are noted in the history of the urban modernity with the new mass media. This article is result of activities of research and practice of the instruction respect the legibility of urban landscape of the city Balneário Camboriú, SC, into of the program Artigo 170 of the government of Santa Catarina and UNIVALI (Vale of Itajaí University).The most important objective was the demonstration, with the city in representation (folders, photografies, cartoons, postals, mental maps), that the tall buildings is not only a cause of imobiliary speculation, but can derive of simbolics signs to the tourism. The methodology was supported by readings of city as fact inverbal and generator of information. The method to begin with the city as object and yours representations as reading; the bibliography only was useful to estimulate the interpretation. Finely, the synthesis was compared whit the support theoric and conceptual.
\end{abstract}

Key words: Urban legibility; Tourism and urban image; Urban landscape and tourism; City-marketing.

Originais recebidos em: 30/09/2008

Texto aprovado em: 06/11/2008

Enc. Bibli: R. Eletr. Bibliotecon. Ci. Inf., Florianópolis, n. esp., 2º sem. 2008 